Cinémas

Revue d'études cinématographiques

Journal of Film Studies

\title{
Remains of the Body in the Classical Hollywood Musical
}

\section{Vicente J. Benet}

Volume 7, numéro 1-2, automne 1996

URI : https://id.erudit.org/iderudit/1000937ar

DOI : https://doi.org/10.7202/1000937ar

Aller au sommaire du numéro

Éditeur(s)

Cinémas

ISSN

1181-6945 (imprimé)

1705-6500 (numérique)

Découvrir la revue

Citer cet article

Benet, V. J. (1996). Remains of the Body in the Classical Hollywood Musical. Cinémas, 7(1-2), 151-165. https://doi.org/10.7202/1000937ar

\section{Résumé de l'article}

Le corps humain, son rôle et sa configuration dans le cinéma classique hollywoodien, présente une vision condensée d'une tension à l'oeuvre entre la narration et le spectacle dans le film. Ayant comme point de départ le musical hollywoodien du milieu des années trente, cet article se propose d'analyser le corps humain dans son rapport à la narration, le montage et la mise en scène, au moyen d'exemples pris dans diverses scènes du film The Gay Divorcee (Mark Sandrich, 1934). 


\title{
Remains of the Body in the Classical Hollywood Musical $^{1}$
}

\section{Vicente J. Benet}

\begin{abstract}
RÉSUMÉ
Le corps humain, son rôle et sa configuration dans le cinéma classique hollywoodien, présente une vision condensée d'une tension à l'œuvre entre la narration et le spectacle dans le film. Ayant comme point de départ le musical hollywoodien du milieu des années trente, cet article se propose d'analyser le corps humain dans son rapport à la narration, le montage et la mise en scène, au moyen d'exemples pris dans diverses scènes du film The Gay Divorcee (Mark Sandrich, 1934).
\end{abstract}

\section{ABSTRACT}

The human body, its role and configuration in Classical Hollywood cinema, offers a condensed view of the tension to be observed between narrative and spectacle in film. With the revival of the musical genre in the mid-1930s as our starting point, this paper proposes to analyze the human body as it relates to narration, montage and mise en scène. Observations are based on examples from various scenes in the film The Gay Divorcee (Mark Sandrich, 1934).

\section{I}

"You have to be an inventor; you have to think of things. I think mechanically, and then I get my engineers and tell them what I want." (Pike and Martin, p. 63) This might have been said by Thomas Edison, Henry Ford or any number of other capitalist moguls, yet it was Busby Berkeley who said it, in an 
attempt to describe the way he worked behind the scenes of his famous musical numbers. A first reading of these words clearly points to a mechanical and technical notion of spectacle in which imagination and invention are supported by engineering. Yet Busby's declaration reveals more than just the bare facts behind a production process. Indeed, it may be understood as a sort of ars poetica, a symptom of a new aesthetic concept linked to real-life experience against the background of mass culture. Taylorization, the rhythm of urban life and assembly lines, cosmopolitanism and an industrial economy tied to global production and scientific advancement... - in sum, any form of new sensibility is inevitably affected by the insistent presence of technology, which comes to be fetishized in art. It is, in fact, in artistic representation that montage, as a point of conflict, gradually defines itself as a fundamental problem. ${ }^{2}$

Engineering and spectacle. What stands out in Berkeley's musical numbers is the uniformity of bodies (particularly women's bodies) and the geometric perfection of which they are a part. Designed to be viewed from the most privileged vantage point conceivable, these musical montages were able to bring order to multitudes of bodies, metamorphosing them into the cogs of a giant visual machine. "In the Berkeley fantasies, whirring pistons, gears and shiny silver metal are represented in absentia by fragmented reiterated parts of the female body assembled in lines and on rotating platforms." (Turim, p. 44) This is, of course, an extreme case, yet it may also be a good starting point for our discussion of the problematic space which the human body occupies in Classical Hollywood cinema as the product of a specific moment in the history of mass culture. Our analysis thus begins by considering the intersection of two dimensions of the performer's body: the anthropological and the historicalcultural. The former has to do with the story line of the film, with narrative as a mode of transmitting experience. The latter is linked to its montage, in which the transformation of reality - as Stephen Kern tells us in his well-known book - gives way to a new culture of space and time. If, as is often said, it is Classical Hollywood cinema that most clearly links the technological mechanics of montage to the ability to tell stories, we 
will need to determine what place the human body occupies within this union. We will therefore attempt to define the status of the body between the two fronts of narration and montage. At the same time, however, we do not intend to overlook the historical aspect of Classical cinema.

As opposed to previous models of film history, more often than not based on generalization and a tendency to homogenize, Rick Altman (1996) proposes a model of crisis. According to Altman, the history of cinema ought to focus more on the problems of specific moments and less on general abstractions. Keeping this in mind, we may observe several of the characteristics of this model in the transition to sound film which took place at the beginning of the 1930s, a time when new narrative strategies were being defined in order to set the patterns for future film genres.

In Classical Hollywood cinema, the relationship between narrative character and the actor's body leads us to consider two separate, but related issues: on the one hand, the issue of character and body as the driving forces in narrative, and on the other hand, the construction of their image strictly grounded in plastic and iconographic effects, that is, directly worked out through the visualization of the body. The two registers appear inseparable and both are part of a historiographic tradition dating back to the writings of Balazs, Delluc's theory of photogénie, reflections on the face and the close up from Walter Benjamin to Jacques Aumont, and feminist analyses of voyeurism and fetishism. In other words, we are dealing with a confrontation between narrative logic on the one hand and imagery and spectacle to the point of "excess" on the other. This "excess," linked as it is to the phenomenalistic dimension of imagery, may be traced back to the very origins of the ideology behind Hollywood film montage since Griffith. In this respect, Tom Gunning ${ }^{3}$ has shown that the establishment of the star system in American cinema, together with the cult-like adoration of actors and actresses, goes hand in hand with the internal tensions leading to the process of narrative integration around 1910 (p. 218). So it is that the actor's body and the image of character come to form a kind of workshop in which the conflict between 
narration and attraction finds expression. The tensions, though closely linked to the spectacular dimension of the image, find direction in the integrating force of the narrative. This, however, does not mean that the strategies of montage within narrative construction were to take precedence over the potency of the image as a phenomenon in itself. Narrative integration merely implies a sway toward narrative, not the submission of every possible resource of imagery at its service. Quite the contrary, imagery and photogenic resistance, in other words, "spectacle" was of capital importance in Classical film narration. Emerging at key moments, spectacle provided an ideal workshop for the treatment and design of actors' bodies. It suspended the spatial and temporal continuity on which the narrative was founded, yet at the same time it was the narrative that tended to integrate the defining forces of "excess."

Attraction and narration enter in conflict in the gap to be found between the actor's body and the image of the cinematographic character. The essence of the latter is founded on both narration and imagery, and its dimensions go beyond the limits of any one, particular film. Typically, the actor's physical presence and the associations the Studios have brought to it through a whole series of movies will determine the shape of the character and our expectations of it. And of course there is also the narrative component to consider, as it plays on the processes of identification and expectation that combine to determine the visual construction of the character. It is, in fact, thanks to the tension between the narrative and visual dimensions of the film that the story emerges, and when we speak of integration in this context we are referring not so much to the idea of one dimension dominating the other, but rather to a symbiosis of the two. The problem, therefore, does not lie in the use of the spectacular to promote the narrative, but rather in the intertextual " excess" that it represents.

We must, however, not overlook the fact that the visual construction of the body is not strictly a problem of narration, but rather one of montage. In his text The Mass Ornament, Siegfried Kracauer analyzes the role of the body in mass culture (p. 76). One of the themes he deals with is the dancers in musicals. Kra- 
cauer observes the existence of formal elements pointing directly to a technical referent: automatism and simplicity of movements; geometry, sequential precision and uniformity; the loss of individuality within a collective process together with the capacity of audiences, the world over, to assimilate and comprehend the spectacle and the generally simple aesthetic parameters on which it is based. Kracauer called this new type of representation, linked to technology and the fragmentation of the body, "ornamental." "Ornamentation is the hallmark of a type of spectacle and entertainment meant to control the masses, and which consists of an accumulation of blocks and fragments that can only make sense when they are combined in an orderly fashion. The relation between entertainment, control of the body and the taylorization of everyday experience in mass society is a central theme in our discussion and it is directly linked to the notion of the body being submitted to the dictates of montage in Classical Hollywood cinema. Mass spectacles are subject to the strict control of a superior geometric will and this is in fact what defines their treatment of the body and subsequent construction of its image. The segmentation and fragmentation of the human body through montage, the lack of correspondence between the body as a whole and close-ups of facial expressions all lead us to believe that montage, as a technical device, is effecting an important change in the way the image of the body is conceived in the spectacles of mass culture.

\section{II}

The advent of sound in movies caused an immediate revision of the traditional views of narration and spectacle which had developed in Hollywood during the silent period. The two basic models of narration and spectacle existing at the time, i. e. melodrama and slapstick, were ousted by systems more in accord with new narrative necessities and the changing design of iconographic elements. The arrival of the spoken word not only permitted a new type of narrative strategy but also a new look at the function of imagery.

The glamour of the star's face, for example, so vital to our understanding of the narrative construction of silent films, was, 
in the "talkies", relegated for the most part to melodrama, emerging at times in other genres as a dense visual device at key moments in the narration. Furthermore, its function as a metaphor was absorbed by other elements of the mise en scène which now opened the door to other options, including the use of the voice and dialogue to achieve characterization. With the advent of sound the genre system was forced to invent a new type of narrative in which the visual effects of silent film discussed by Bazin might be recovered through their integration into a more realistic type of discourse.

The process of integration and narrativization that we will be referring to here is tied to the establishment of new cinematographic genres after sound. The narrative patterns of the condensing and episodic structures in melodrama or slapstick will dissolve into a new type of narration whose structure is based on the psychological verisimilitude of the characters' actions, which are now subject to a whole system of motivations in keeping with the dictates of the narrative process. All in all, the idea is to provide the stories narrated in films with a temporality that excludes the density of the moment, the suffering gesture, the comic pirouette, extending their effects throughout the general corpus of the narrative. At the same time, the effect of narrative integration also depends on the presence of some type of imagery, on the construction of the spectacle within each specific genre, in order to set up a framework for what may be accepted as believable by the audience.

\section{III}

There is perhaps no genre like the musical when it comes to analyzing the problems we are discussing here. The direct offspring of technological innovation, the musical is not based on any traditional genre prior to cinema, though some of its narrative registers do have their origin in vaudeville, the operetta or theater. Theoretical approaches to the musical tend to discuss the relationship between the structures of spectacle within the genre either in terms of the appearance of music and/or dance or in terms of the elaboration of a story based on motivations and causal logic. The disruption implied by the spontaneous ap- 
pearance of spectacular scenes in musicals is mediated by the intertextual effect they create. This intertextual effect is in fact what makes it possible for the interludes of spectacle to be absorbed within the film's general register of verisimilitude without affecting the story line. The actor's body undergoes a kind of metamorphosis in these scenes, allowing a character to instantaneously become an entertainer or performer. It is this capacity for transformation, the idea of bodies able to spontaneously change into dancers or singers, which forms the central theme of our discussion here.

Within the framework of text reception, the cultural effect of spectacular disruptions in the story line may be interpreted on a number of different levels. Jane Feuer, for example, points out that the mise en scène, together with narrative, makes it possible to maintain an effect of verisimilitude throughout the film. In her words,

During the narrative interludes [...] we are encouraged to share the point of view of the performers, but during the musical interludes, we are encouraged to actually become part of the audience in the film - a very different and much closer type of identification. [...] Since the perspective of the performers has already been established through the narrative (or through our prior acquaintance with the film's stars), it is perfectly possible for us to experience a doubled or split identification during the performance without ever experiencing this split in our consciousness as disconcerting. (1987, p. 29)

The relationship between narrative interludes and performance (or musical interludes and narration, depending on one's point of view), allows for two different types of audience identification. One is through spectacle, by designating a place for the spectator within the representation. For example, in the backstage musical we are shown the house seats in a theater, and in other subgenres there are diegetic spectators present. The second type of identification, known as "secondary identification," has its roots in the narrative, and the possible correspondence of hero and spectator through focalization or point of 
view. Feuer's ability to separate the two types of identification in such a simple manner is noteworthy. Such a stance, however, would veer us away from an integrated view of narrative and spectacle, which is precisely the aim of the Classical model.

Choosing a different point of departure from which to begin his analysis of the issue at hand, Rick Altman (1987) proposes the interesting theory that the dominant paradigm in musicals is clearly to be found in narrative. Altman begins at an empirical level, but at no moment overlooks the intertextual and cultural dimension of the genre. Thus, the narrative structure of the musical is not based on a linear or causal process tied to the main character's trajectory, but rather on a dual focus narrative played out by two stars of opposite sexes and opposing values. Many of the story's possible options are defined, a priori, by expectations as to what is typical of the genre from its very beginnings. From shorts of musical numbers used to present the technological innovations of the day or to fill out movie sessions, to the fulllength musical features that brought the different numbers together in one story, there is an intense process of assimilation occurring throughout the first three years of the history of the musical, at least. ${ }^{5}$ As for the narrative peculiarities of the genre, Altman suggests that the plot may be seen as a process in which a series of oppositions are progressively reduced by the narrative, and differences are slowly eliminated so that a final union may be reached. Hence, we are no longer dealing with a segmental structure based on a paradigm of causality and progression (a structure of an $\mathrm{A}->\mathrm{B}->\mathrm{C}$... type), but rather with one of parallelism and confrontation (A / B , C / C'...).

According to Altman, this type of structure has several implications regarding the place of the musical within the Hollywood genre system. On the one hand, the character now plays a central role in the plot - not because of his actions but rather due to the symbolic elements (social, cultural, sexual, etc.) that he or she represents. On the other hand, the very fact that a narrative structure of this type is no longer so dependent on plot allows for and facilitates the presence of the spectacular, of performance-related elements more apt to interrupt the story line. Thus, performance interludes within the musical may now 
be seen to function as "punctuation marks" within the general makeup of the story, offering periodical summaries of the narration :

Once we have understood the dual-focus approach we easily grasp the importance of the many set pieces of production numbers which some see as cluttering the musical's program and interrupting its plot. The plot, we now recognize, has little importance to begin with; the oppositions developed in the seemingly gratuitous song-and-dance numbers, however, are instrumental in establishing the structure and meaning of the film. Only when we identify the film's constitutive dualities can we discover the film's function. (1987, p. 27)

What is interesting to note about Altman's proposal is his idea of the weakness of the plot. In keeping with this idea, Altman, unlike Feuer, analyzes neither the complexity of the mise en scène nor the role of editing in the transitions we are discussing here. What's more, Altman makes no distinctions between different levels within narrative and spectacle. Hence, both editing effects (such as audio dissolve - diegetic sound to music, or video dissolve - transition from the diegetic world to the ideal world of spectacle) and narrative effects (personality dissolve: the transformation of the hero into a singer or dancer) receive the same treatment in Altman's analyses.

Nevertheless, Altman's interesting formulations regarding the definition of the musical narrative are, in our opinion, limited for several reasons. The main point on which we disagree with Altman lies precisely in his thesis regarding the internal weakness of the story. If the story were really of such negligible importance, the disruptive capacity of the visual would not be so traumatic to its continuity. A rather telling characteristic of the narrative configuration typical of the genre we are discussing is its treatment of time. As Altman sees it, it actually appears to contradict the logic of other Hollywood narrative models: "This dual-focus structure requires the viewer to be sensitive not so much to chronology and progression - for the outcome of the male/female match is entirely conventional and thus quite predictable — but to simultaneity and comparison." 
(1987, p. 19) As opposed to integration, or the elaboration of a narrative model which would permit the coherence of the story through the plot, Altman postulates that the narrative construction of musicals based on a dual-focus structure intentionally includes a series of open slots in which musical numbers may be incorporated. These musical interludes would no doubt be disruptive in a narrative structure based on continuous progression, but not at all traumatic within a structure based on simultaneity. According to Altman, then, narrative time does not form the basis of the story or plot in musicals, but rather it is kept in a kind of "freeze," and the distance between beginning and end is minimal. Musical numbers may thus be inserted into the "frozen" story at any moment, and their function then becomes one of illustrating and resolving the protagonists' ups and downs, while at the same time maintaining a certain independence from the precarious progression of the plot.

As we see it, the problem in Altman's text arises out of a need for a more in-depth (and historical) look at mise en scène and montage in the various phases and subgenres of the musical. The elaboration of the spectacular lies not in stable, generic formulas but rather with formulas linked to a specific moment in the history of the Hollywood model. I would like to begin my analysis with a specific example which reveals the tension between narrative and spectacle as it is portrayed in the characters and bodies of the actors of a well known musical film, The Gay Divorcee (Mark Sandrich, 1934).

According to Altman's thesis, The Gay Divorcee is a fairly conventional example of dual-focus narration developed in the contrast between Guy Holden, the dancer (Fred Astaire) and Mimi Brown/Green, the unsatisfied wife (Ginger Rogers). It is through this conflict that the characters come to life. Nevertheless, they are not complete opposites. In fact, the two share certain symbolic characteristics that actually make them more similar than different. The conflict between them thus arises from the construction of the plot. The initial opposition is portrayed in Guy's attack and his overtly aggressive sexuality which brings out a defensive or hysterical reaction in Mimi, typical of the heroines in this type of story. Yet there are other formal mecha- 
nisms contributing to the structure of the narrative which are fundamental to our understanding of the overall characterization of the protagonists and the way they function within the film as a whole. On the one hand, the secondary characters of the film are continuously placed in comical contrast to each other, in such a way that the device of role reversal triggers a grotesque sort of representation of the battle of the sexes. Such is the case of Mimi's promiscuous aunt (Alice Brady) and Guy's asexual lawyer friend (Edward Everett Horton). But the most important narrative effect in the film, the thing that lends cohesion to a whole chain of mishaps and double entendres has to do with the position of the spectator with regard to the story. What is essential to both the comic and dramatic effects of the film is the fact that the spectator always knows more about the facts of the plot than the characters do. The spectator is, in other words, in a privileged position, and the effectiveness of the musical scenes disrupting the narrative depends on this. The metamorphosis of the protagonists' bodies into magnificent dancers (despite the diegetic justification that Guy Holden is a professional dancer) may only begin to be understood in keeping with the idea of the spectator's privileged viewpoint. This is especially important in The Gay Divorcee because it is the first picture featuring Astaire and Rogers as the main stars and therefore destined to set the pattern that their later films would intertextually assume.

Two of the film's musical numbers exemplify this: the romantic dance number of "Night and Day" and the grand performance of "The Continental." The former is the only Cole Porter song remaining from the original show (Barrios, p. 430) which Astaire himself performed both on Broadway and in London. Following The Gay Divorcee, the romantic dance between Astaire and Rogers became the climax of all their subsequent films. The sequence thus merits a closer look. After a series of conflicts Guy and Mimi find themselves reunited in a hotel ballroom where they make up under a star-filled sky. The two are enveloped in an atmosphere of romance, and as the inevitable declaration of love gradually draws near, the melody of "Night and Day" begins. Guy sings as space, rhythm, and melody are 
all broken up by the editing of the scene. The fragmentation of space is minimal - barely five shots using a frontal axis and a brief pan of the characters, following them as they move through the set. But when the words of the song end, another scene is brought in. "Brought in" because the editing marks an obvious transition. In the last shot of the song itself the protagonists exit to the right. Immediately after this the next shot shows them preparing to begin the dance.

The segmentation of the dance sequence in thirteen shots is much more elaborate than that of the song fragment. The key here is that there are three main camera positions following the choreography: one from the front, and two from the sides, with a slightly larger than forty-five-degree variation between the angles. As Altman says, "Astaire and Rogers appear to be on stage, with the camera-operator sitting in that proverbial fifth row." (1987, p. 41) It is important here to keep in mind that the ceremony of seduction through dance is fundamental to the narrative structure of the film. Yet the narrative function of the scene is transcended through montage, responsible for the fragmentation of space and symbolic construction of the bodies on stage. A whole series of visual effects frames the protagonists' bodies within each shot. The three camera positions mentioned above offer us distorted images of the dancers through window shades, from between table legs or in the redundant presence of an enormous window opening up onto the romantic evening outside. All in all, the montage work behind the composition of the different shots, angles, and deformed images is meant to achieve an effect of spectacular excess.

The editing strategies used in the dance scene are different from those which characterize the rest of the film. Interestingly, some of the shots in this sequence do not actually allow us to clearly see the protagonists' bodies as they dance. The visual apotheosis represented in the scene is achieved not only through a break in the verisimilitude of the stars' behavior as they are driven to dance by music, but also through the editing of the sequence. The scene must therefore also be understood as a climax in the narrative of the film, beginning as it does with the dancers' carefully planned movements across the stage and the exaltation 
of the body through montage in each shot. As Feuer says, the characters clearly transcend their narrative function and become performers. It is the montage of the scene which allows us to see them as such, radically changing the strategies it maintains throughout the rest of the story. Still, the transition between narration and performance is clearly balanced through the effect of the mise en scène. This effect is achieved through both variation in montage and the exaltation of the body, at the same time that there is a kind of control and rigidity to be observed in the set layout, in its role as ultimate referent. The same formula described here will then go on to become a prototype for the elaboration of dance numbers in later movie musicals and will be endlessly repeated in the following decades of American cinema.

In contrast to this, the performance of "The Continental" in The Gay Divorcee is entirely different. To begin with, the main object of this fragment does not lie in any narrative function, but rather in the special nature of the dance number itself. The notion of scene is totally different here and the unity of the set is continually broken up. The various segments of the sequence may be defined in terms of variety. Three are sung, two are dances performed by Astaire and Rogers and there are also various group segments with a large number of dancers. The set layout for the Astaire and Rogers dances is minimal. Of greater interest here is the montage work in the group segments, characterized by a spectacular architectural framework in which cranes have been used to provide a full view of the splendor of the dance. The most remarkable aspect of the scene is, however, the complete dissolution of time and space which is achieved through editing in order to reveal the geometric formations of the group number. Contributing to the kaleidoscopic effects of the dance is the chromatic extravagance of the performers' costumes. There is no specific orientation to the transitions between shots in this segment, and the compositions reveal the plastic qualities typical of the montage sequences. The cameras are positioned in such a way as to provide a full view of a geometrical spectacle in the style of Busby Berkeley, though in this case things are not carried to the extreme of total spatial and temporal abstraction characteristic of his musical numbers. 
There is no balance here between narration and performance, and the mechanism which might provide it - the human body - disappears. The segmentation of the group numbers turns the parts of the body into autonomous entities, with the result that arms, legs and faces all become moving cogs within a visual machine. An incredible succession of shots in the final crescendo of "The Continental," each lasting less than a second, draws us into this visual machine, from which any notion of balance is clearly excluded.

In our opinion, it is symptomatic that this type of gigantic musical number, first seen in the Carioca of Flying Down to Rio (Freeland, 1933), would disappear with the Piccolino from Top Hat (Sandrich, 1935), the film in which Astaire and Rogers starred the following year. During an initial phase of visual experimentation in musicals, some balanced formulas (like that of "Night and Day") proved to be effective in the construction of the plot, while others were relegated to a kind of subgenre, or extravaganza style. Even in the films in which they were used, numbers of the latter type were generally placed at the end of the story in order to avoid their disruptive effects. What's more, this phenomenon was limited to the initial stages of the careers of Astaire and Rogers, coinciding with the resurgence of the musical genre around 1933-34 in films produced by RKO and Metro, as well as in Warner's Busbsy Berkely musicals. Against this background, then, the role of the human body and its adaptation to the narrative and visual necessities of every film is key to the discovery of the balanced formulas destined to survive within the Classical Hollywood model, at the same time that it will determine which formulas, marked by the specificity of a given context, will tend to disappear.

Universitat Jaume I (Castelló-Spain)

\section{NOTES}

1 This essay is part of a research project funded by the Plà General de Ciència i Tecnologia (Generalitat Valenciana) in Valencia, Spain. I would like to express my gratitude to Susan Hoover and Justine Brehm for the translation of the text.

2 For an introduction to the problem of montage in relation to mass culture, see V. Sánchez Biosca, Teoría del Montaje Cinematográfico (Valencia: Textos de la Filmot- 
eca, 1991) and Maud Lavin et al. Montage and Modern Life (Cambridge: MIT Press, 1992).

3 The concept of narrative integration proposed by Gunning is used here within a proper historical perspective. We do not, of course, consider the narrative integration characteristic of early cinema as identical to the new narrative strategies which will be used later on in sound cinema, and which we are discussing in this study. Nevertheless, we are convinced that the notion of narrative integration is fundamental to an understanding of the reformulations of genre which will progressively come to do away with many of the paradigms traditionally found in melodrama and slapstick. At the same time, the notion is also of key importance in coming to terms with the restructuring of the narrative, visual and symbolic components of films after 1927.

4 "A current of organic life surges from these communal groups - which share a common destiny - to their ornaments, endowing these ornaments with a magic force and burdening them with meaning to such an extent that they cannot be reduced to a pure assemblage of lines. [...] The patterns seen in the stadiums and cabarets betray no such origins. They are composed of elements that are mere building blocks and nothing more. The construction of the edifice depends on the size of the stones and their number. It is the mass that is employed here. Only as parts of a mass, not as individuals who believe themselves to be formed from within, do people become fractions of a figure." (Siegfried Kracauer, The Mass Ornement. Weimar Essays, Cambridge: Harvard University Press, 1995, p. 76)

5 Some of the first full-length musical films consisted of nothing but a series of independent numbers connected by the presence of a well-known artist or gags featuring some of the big studio stars of the time. See, for example, Paramount on Parade, Janis, 1930 or Show of Shows, Warner, J. Adolfi, 1929. Interestingly, this pattern may be seen to survive as late as 1946 in Vicente Minelli's Ziegfield Follies.

\section{WORKS CITED}

Altman, Rick. "Pensar de otro modo la historia del cine». Archivos, n" 22 (1996).

Altman, Rick. The American Film Musical. Bloomington-London: Indiana University Press, 1987.

Barrios, Richard. A Song in the Dark. The Birth of the Musical Film. New York: Oxford University Press, 1995.

Feuer, Jane. The Hollywood Musical. Londres: B. F. I., 1982.

Gunning, Tom. D. W. Griffith and the Origin of American Narrative Film. Urbana \& Chicago: University of Illinois Press, 1991.

Kern, Stephen. The Culture of Time and Space 1880-1918. Cambridge: Harvard University Press, 1983.

Kracauer, Siegfried. The Mass Ornament. Weimar Essays. Cambridge: Harvard University Press, 1995.

Lavin, Maud et al. Montage and Modern Life. Cambridge: M. I. T. Press, 1992.

Pike. Bob \& Martin, Dave. The Genius of Busby Berkeley. Reseda: C. F. S. Books, 1973.

Sánchez Biosca, V. Teoría del Montaje Cinematográfico. Valencia: Textos de la Filmoteca, 1991.

Turim, Maureen. "Symmetry/Asymmetry and Visual Fascination". Wide Angle, vol. 4, n³, 1980 . 